\title{
Untying Blake's Secular Scripture
}

\begin{abstract}
Rlake criticism, under the aegis of Frye, has until recently assumed $B$ the coherence of his work by composing it according to the hermeneutic code of his later system. The system is not a synchronic entity, and indeed that is why we have had recourse to a hermeneutic in order to find it in texts where it is not clearly present. In line with the divinatory readings developed by post-Kantian idealists like Schelling and Hegel, the 'mature' Blake represents his early texts as shadowy types of the later work and figures the latter as still evolving. The dissenting energies of some of the early texts are thus bound within the stubborn structure he was trying to build as he proceeded from a multitude of small poems, through the antechapel of the minor prophecies, to the philosophic poem that he alone among the romantics actually approximated.
\end{abstract}

Insofar as Blake himself encourages canonical reading, while at other times stimulating resistance to it, his work is centrally involved in the dissemination of a traditional hermeneutic. The figure of the canon brings together the cultural ambitions of the hermeneutic tradition as we have traced them in the three previous chapters. Not only does it employ reading synchronically to claim consensus, as Wordsworth tried to do, it also develops the diachronic dimension of hermeneutics by using the supplement of history both to claim future authority and to contain textual contradictions within a teleological narrative. The Bible, which Blake described as the great code of art, has been the model by which both we and he have read his secular scripture. Assembled out of the writings of many men and conjoining two distinct cultures, it provides analogies not only for a unification of the authorial canon but also for a 
hermeneutics of cultural history that we may now see as imaginative imperialism. In the reading of the Bible, radically different texts are made to advance a narrative that becomes clear only later in history. In actuality, the Bible is not an eschatological narrative, but a collection of writings that inscribes the holoscopic impulse in an intertextual field. When we refer to it, however, we refer to an editorial activity supervised by the institutional church. This activity produces a cultural paradigm that typologically absorbs difference into unity: a paradigm in which all religions are made to be one.

In the later prophecies Blake experiments with a self-canonization that submerges those differences from himself that he dismisses in The Everlasting Gospel as "Self-Contradiction" $\left(\mathrm{E}_{52} 2\right.$; l. 92). But the system is a later supplement, and the presystematic texts are very different from the late ones. We must remember also that the Blake who used the biblical paradigm to limit reading was profoundly influenced by gnostic heresies that questioned the authorized version. ${ }^{1}$ Gnosticism rather than Protestantism made possible Blake's radical humanism as well as his antiinstitutional belief in the individual as the source of gnosis. This emphasis on the individual challenged belief in a single scriptural canon or a single reading of it. For as Elaine Pagels suggests, the gnostics, though they sought one truth and were not relativists, regarded all doctrines and myths including their own "only as approaches to truth."2 Given the existence of the heresies, the forming of a scriptural canon had for centuries been the scene of a struggle in which doctrinal questions were entwined with political issues such as the status of women and the democratization of the structures by which religious knowledge was transmitted. ${ }^{3}$ Like Wordsworth, Blake inherited these issues as part of the archeology of his chosen genre. As he composed his secular scripture, he was forced to consider whether there were not voices and perspectives excluded by the activity of canon formation and thus to assess the legitimacy of his project.

These chapters will be concerned with Blake's heresies against his own system. The work of Damrosch and Mitchell, as well as the essays collected in Unnam'd Forms, ${ }^{4}$ have already made us aware of a nonsystematic Blake. Drawing on such studies but focusing on texts in the larger context of Blake's corpus and on the canon itself as a cultural form, I try

\footnotetext{
${ }^{1}$ On the general provenance of gnosticism in the romantic period, see James Rieger, The Mutiny Within: The Heresies of Percy Bysshe Shelley (New York: George Braziller, 1967).

2The Gnostic Gospels (New York: Vintage, 1981), p. 137.

3See ibid., pp. 49, 70-74, $125-28$.

${ }^{4}$ Leopold Damrosch, Symbol and Truth in Blake's Myth (Princeton, N.J.: Princeton University Press, 1980); W. J. T. Mitchell, Blake's Composite Art: A Study of the Illuminated Poetry (Princeton, N.J.: Princeton University Press, 1978); Nelson Hilton and Thomas Vogler, eds., Unnam'd Forms: Blake and Textuality (Berkeley: University of California Press, 1986).
} 
to reconceive what might otherwise become scepticism or aporia as generating a revisionary hermeneutics in which intertextuality replaces canonicity. For the early Blake did not simply write poems that failed to resolve themselves into a system. He created a counterpractice that encourages us to reflect on the very processes of interpretation and institutionalization, though one that is still a 'hermeneutic' in that it involves writer and reader in a process of cultural self-understanding. Accordingly, the present chapter is a theoretical one, which plays traditional arrangements of Blake's canon against an admittedly heuristic remapping of the textual field into three 'sectors.' In keeping with our convention of beginning with theoretical paradigms developed by the writers themselves, it treats Milton as a fictionalized elaboration of the hermeneutic on which canonical readings rely, while using The Marriage as a 'source' for the early Blake's counterpractice. This counterpractice finds expression in a writerly use of form that is phenomenological rather than postmodern and that therefore generates a perspectivism that is not relativism. Focusing on Blake's early texts, the subsequent chapters deal with two sectors of his work as perspectives from which to view the canon he subsequently constructs. Thus, the earliest poems allow us to view experience from an individual rather than systematic perspective, and by inviting intertextual rather than teleological reading, they question any narrative into which we might fit them. In the brief epics that are the subject of the third chapter, Blake begins the construction of a narrative to contain individual episodes, but in a manner that calls for constant rereading.

The Early Texts and the Displacement of the Canon

Any description of how Blake displaces his canon must begin with the differences between the early and late texts. For not only does the shared use of biblical patterns make the two seem continuous. Sometimes editors further emphasize this continuity by divisions into 'minor' and 'major' prophecies, in which poems like Thel that are in no sense prophetic are typologically absorbed into the category of minor prophecies so as to blunt their dissenting force. ${ }^{5}$ One area of difference is suggested by Leslie Tannenbaum, who argues that while the Lambeth books, like the Bible itself, compose a secular scripture from "a number of disparate books," the later prophecies fuse "biblical prophecy with the

${ }^{5}$ I refer here to the popular edition by Northrop Frye, Selected Poetry and Prose of William Blake (New York: Random House, 1953). 
epic mode, casting the entire vision of the Bible in a single work." 6 Although he is arguing for the unity of Blake's oeuvre, the early use of what we shall call 'segmented' form generates questions about the epic totality later developed to sublimate the differences embedded in the great code itself. These questions may well persist in later texts whose totality is not explicitly under erasure but which, as David Clark has shown, turn out on closer inspection to be "self-displacing." 7 Nevertheless, the two groups of texts are vastly different as frames through which to view the textual field. The whole in the epics claims a rhetorical precedence over the parts; in the earlier texts it is the parts that precede their assemblage into wholes that may be no more than interpretive constructions.

Perhaps more accurate than a genetic arrangement that marginalizes the earlier texts as 'minor' is a division of Blake's work into three 'sectors': the early poems (such as the Songs, Visions, and Thel), the brief epics from The Marriage of Heaven and Hell to the Lambeth period, and the longer prophecies, which most clearly articulate the system. The differences between the earliest and final texts are the most striking. Although the former contain characters and symbols later absorbed into the system, they are not yet part of a macro-poem that Blake, as medium for the world-historical spirit, is involved in constructing. They connect with each other, but dialogically rather than anagogically. Their perspective is not yet cosmic: like the Lyrical Ballads, the Songs are spoken by a heteroglossia of individual voices, whereas Thel and Visions provide inside views of the experience of one character. Told as they are from an individual perspective, they suggest to us that experience or experiment may have priority over any preestablished system. In the longer prophecies it is precisely this emphasis on experiment that disappears, as particularized symbolic characters are replaced by mythic characters with whose selfhood the reader is not supposed to identify, and who are therefore sketched in structurally as actants rather than phenomenologically as selves. These characters function allegorically, not in the sense that they stabilize reference in a system of one-to-one correspondences, but in the sense that their referent is an argument (however selfcomplicating), and not an 'inside,' a personality. Gone also is the conspicuous assemblage of texts in terms of short, monad-like sections. This method of presentation had created a certain resistance to totalization, being a structural marker of the recognition that the whole is always less than the sum of its parts.

${ }^{6}$ Biblical Tradition in Blake's Prophecies: The Great Code of Art (Princeton, N.J.: Princeton University Press, 1982), p. 7 .

7"Auguries of Difference: Indeterminacy and Displacement in Blake's Prophetic Texts" (Ph.D. dissertation, University of Western Ontario, 1986), p. 71. 
Somewhere in between these two poles are the brief epics. For though they share with the earliest texts a composition in terms of disjunct, mobile parts, they also share with Milton and Jerusalem the project of a secular scripture. The holoscopic intentions of the brief epic are described by Barbara Lewalski, who sees it as sharing with epic a proposition or invocation, a rising action that moves toward victory, and a hermeneutic claim to provide a compendium of all knowledge. ${ }^{8}$ Europe and America clearly have rising actions, and the various introductions and preludia of the Lambeth books occupy the structural position of propositions, whether or not they provide a key to the action. Unlike its longer cousin, the brief epic concentrates on a single episode and does not begin in medias res so as to unfold the story of things archeologically and teleologically from an event that is made the metaphysical center of a phenomenology of spirit. But the totalizing effect created in the larger form by the text's ability to move forward and backward in time is supplied in the brief epic by the use of typological symbolism, which enhances the "epic dimension" by giving the particular episode a paradigmatic significance. ${ }^{9}$ Blake's system, we can argue, similarly functions as an "abstracted typology" 10 that transposes the episode from diachronic and historical to synchronic and mythic time. Also characteristic of the brief epic, as Lewalski points out, are spectacular scenes: ${ }^{11} \mathrm{a}$ series of tableaux whose melodramatic or apocalyptic staging inhibits complex response and asks us to see events in black and white patterns. Spectacle, to put it differently, subordinates event to rhetoric rather than allowing experience to complicate argument:

In contrast to the early texts, the force that drives the brief epic is a totalizing one. Moreover, where dialogue and counterpoint dominate the early texts, speech in these poems has become oratorical. Nevertheless, Blake's brief epics are also sites at which this totalizing impulse is challenged. To begin with, the brief epic is, in de Man's sense of the word, 'intentional': it inscribes epic as desire. The Lambeth books are only preliminary sketches for Blake's global vision, and their very brevity suspends their claim to finality. Thus, in Europe the poem breaks up into a series of flamboyant happenings that leave us uncertain whether its climax is central or peripheral, an episode or a paradigm. Moreover, although we feel in the poem what Mitchell calls a "pressure for resolu-

${ }^{8}$ Milton's Brief Epic: The Genre, Meaning, and Art of Paradise Regained (London: Methuen, 1966), pp. 21, 26, 31 .

9Ibid., pp. 64,45 .

${ }^{10}$ Paul Korshin, "The Development of Abstracted Typology in England 1650-1820," in Earl Miner, ed., Literary Uses of Typology from the Later Middle Ages to the Present (Princeton, N.J.: Princeton University Press, 1977), pp. 147-203.

${ }^{11}$ Milton's Brief Epic, p. 83. 
tion," 12 the precise meaning of the resolution is far from clear in this text whose claim to be a 'prophecy' can only refer to how it is spoken and not to what it says. The liminal structure of the poem, which takes us to but not across a threshold, collapses the encyclopedic perspective of eighteen hundred years into a sense of the text as an episode. This marking of the text as installment is even clearer in Urizen, which begins by reminding us that we have read only the first book. As the installments accumulate, but without following a pattern of advance or decline, 'epic' increasingly comes to seem transcendent, a matter of the formal covering rather than of the inward content, which remains, in Hegel's term, "indeterminate." As in Hegelian hermeneutics, these poems invite us to resolve the gaps between theme and execution through a divinatory reading that constructs the whole into which they fit. But such resolutions are constantly suspended by the tension between epic rhetoric and brevity of form. Related to the problems of brevity and indeterminacy is the use of the spectacular, which emphasizes appearance at the cost of what lies behind it. Spectacle, though powerfully oratorical, is uncertain in the truth-claim it makes. Hyperbolical in its structure, spectacle is a mode of excess that hovers between overstatement and apocalyptic wisdom.

The totalizing impulses of the early prophecies are similarly arrested by the form they share with the early poems. Briefly, Blake uses a modular form organized around juxtaposition rather than continuity. The early texts are made up of discontinuous discursive segments, sometimes spoken by different voices. Though we encounter them in a certain order, they do not simply unfold into each other: they function as mutually reflecting mirrors that make the reading experience recursive. Perhaps the most extreme example of this disjunctive structure is The Marriage of Heaven and Hell, which combines poetry and prose, aphorism, logical discourse, fantasy, and prophecy. More common is a conjunction of preludium, narrative, and a further preface or motto: a form we find in Thel, Visions, Europe, and Urizen. Often, the meaning of these components is less clear than their structural function, so that there is a defamiliarizing of this function in which the text's form becomes its content. Thus, mottos do not simply provide guidance but raise the question of whether there is a key to the text's meaning. Introductions do not simply lead into the narrative but make us reflect on whether the narrative is shaped by the point at which we enter it. The resulting reflection on perspective is encouraged by the relative spatial autonomy of these segments. The parts are foregrounded in a radical challenge to the hermeneutic circle with its organicist notion of a correspondence be- 
tween part and whole. The 'whole,' instead of being what the parts fit into, is a perpetually shifting effect of the (part)iculars through which we view it.

Segmented construction characterizes even the texts whose plates are in a relatively fixed order. But Blake also makes his parts movable by varying the order of the plates and leaving them unbound. He thus creates what Barthes calls a 'writerly' text which the reader cooperates in making. ${ }^{13}$ The writerly text denies to itself a canonical form and makes us aware of its truths as a field of metaphors that we structure by inscribing in it our own further metaphors. The order of these texts is not infinitely variable, because a poem like Thel will of ten have page numbers. Nevertheless, Blake did not paginate components like mottos, frontispieces, and tailpieces, and thus provided a heuristic stimulus to the reconception of the text as flexible rather than dogmatic. Leopold Damrosch, one of the few critics to recognize that the transferability of parts calls into question an organic conception of the text, sees this extraordinary use of form as creating a synchronicity characteristic of myth. ${ }^{14}$ But although it is true that an open form unbinds us from the mimetic claims of chronology and allows for visionary rearrangements that defy historical limits, mobile forms open windows into eternity only as part of a perspectivism that reinscribes vision in a field of relations. These relations are necessarily cultural and experiential. Refusing to make the poems embody what Damrosch calls "a single and inevitable form," 15 Blake does two related things. He opens his text to the fact that readers (including Blake himself as reader of his texts) see things differently depending on who they are and when they live. He also opens us to the fact that psychological and historical constructions of the self are not forms of determinism but 'states' that we temporarily inhabit.

The field of possibilities which constitutes such a text is generated not only by the shifting relations between its parts but also by the relationships between poems that cite and revise each other. Blake's patrons made their own relationships between texts, binding certain poems together and thus constructing different 'canons.' The intertextual structure of these poems obviously qualifies any claim by the prophetic mode to provide a divinatory reading of cultural history. Thus, the relatively hopeful prophecy of America is accompanied by a preludium whose dark virgin recalls the shadowy female of Europe. The ambiguity of this seg-

\footnotetext{
${ }^{13}$ There is some debate over whether the various orders in which the plates survive were sanctioned by Blake. But as Robert Essick points out, his method of printing allows that readers do different things with texts, and that the text may be partly constructed by the accidents of transmission. "William Blake, William Hamilton, and the Materials of Graphic Meaning," ELH 52 (1985): 841, 868.

${ }^{14}$ Symbol and Truth in Blake's Myth, p. $35^{1 .}$

${ }^{15}$ Ibid.
} 
ment, which may suggest that this revolution, too, will produce a fruitless implosion of energy, is compounded by a further segmentation in which Blake covers up in some copies the lines that depict the bard breaking his harp. The position of this segment, whether the bard is "asham'd" $\left(\mathrm{E}_{52} ; 2: 18\right)$ of the doubts expressed in the preludium or of the hopes expressed in America itself, is likewise unclear. The indeterminate relationship of the poem's segments generates further questions about the relationship of Europe and America in Blake's cultural narrative. The fact that the preludium was added later may make it a European revision of American optimism in the light of experience. Or it may limit the authority of the preludium by suggesting that its mood was colored by the writing of Europe. The point is not to choose between these interpretations, but rather to recognize the implications of Blake's structure for a substantialist conception of the text. The spaces between segments are spaces in which readers must think about the cognitive categories they use to relate these segments. Moreover, in constructing our own version of the relationship between the segments, we also become aware of critical sub-versions in relation to which our own (current) version can do no more than maintain itself as a diacritical possibility.

Most of Blake's early and middle texts are composed of movable segments that make us think about structure and perspective. This method, though still present in later works, is less conspicuous because the main narrative takes up so much more space in relation to the prefaces and preludia, and because the densely packed print of Jerusalem is less interrupted by full-page designs. The segmented construction of individual texts carries over into the macro-poem Blake may have been trying to assemble out of them in his middle phase. Stationing ourselves at the beginning of that project, we become aware of how the secular scripture is assembled out of parts that do not make a whole, produced if not by different authors at least by different 'Blakes.' We can read a poem like The Song of Los as a frame for America and Europe, so as to make the assembled structure into a narrative that proceeds from creation to apocalypse. ${ }^{16}$ As the poems are written, however, the 'frame' is consciously supplementary in the way it telescopes beginning and end together in a separate text, without being able to integrate them with the middle from which the end must grow if it is to be persuasive.

In fact, Blake's canon bears an uncanny resemblance to his great code. The early texts and brief epics are his old testament. Written in vastly different styles, they are poems of exile and experience whose liminal hero Orc is a god of wrath as much as of energy. Where these texts are 
scattered episodes from a story that does not yet exist, the longer prophecies are parallel versions of that story, told in Jerusalem on a cosmic scale and in Milton on an individual scale. In their coherence of purpose they are much more like the gospels, which they resemble in substituting Los for Orc, the order of mercy for that of wrath. But if the Bible provided an imaginary identity for Blake's texts within a typological series, the genre of secular scripture also functioned as the ballad did for Wordsworth, as a mirror-stage. Blake was aware of the new developments in biblical hermeneutics, and specifically of the detailed philological work that called into question the authority of the Bible as the product of a creative spirit with a single purpose. ${ }^{17}$ Schleiermacher was shortly to take the radical view that discrepancies in the synoptic gospels could not be explained as later accretions, that they constituted layered readings of indeterminacies in some of the pivotal events of the Christian story. In some sense Blake was drawn to the scriptural analogue precisely because it was dangerous as well as reassuring. The fundamental indeterminacy of those primal cultural scenes that 'explain' the human condition is something he encounters repeatedly, and it is such indeterminacies that generate the multiple perspectives from which the texts read themselves.

\section{Reading the Vortex: Milton and the Reconstruction of a Canon}

Although these chapters attempt to unsettle a canonical reading of Blake, that reading is one that he himself later inscribes in his work. In Milton Blake begins the task of creating a canon by imagining a scene of reading that will contain previous errors: his own and those of cultural history generally. As a writer who returns from the dead to become his own reader, Milton limits the disseminative potential of the writerly mode by modeling it for us. He becomes his own prophetic reader: he reorganizes the chaos of his past from a higher perspective, by unearthing from it that subtext that made him a member of the devil's party without his knowing it. His divinatory reading takes form as repentance, as a hermeneutics of charity that finds value in errors that become the impetus for truth. As a figure for the stable interchange of writing and reading functions, Milton is also Blake as his own reader and Blake's desired reader. He acts out a way of organizing a text like The Four Zoas, which was a workshop where Blake drafted material for the final prophecies and stored what he could not yet assimilate. Sublated into Milton, Blake's unengraved epic is his first attempt to construct a

${ }^{17} \mathrm{Cf}$. Jerome McGann, "The Idea of an Indeterminate Text: Blake's Bible of Hell and Dr. Alexander Geddes," Studies in Romanticism 25 (1986): 303-24. 
whole out of the parts into which it kept collapsing. The Four Zoas is in turn a synecdoche for the earlier poems, with their oversignification of part over whole.

Milton also humanizes for us the abstractions of Christian hermeneutics, by coupling them with an interiorized self-exegesis remarkably like psychoanalysis, though protected from the latter's tendency to deconstruct the self by its association of understanding with charity and salvation. The Puritan poet descends into his past self through a selfdisplacement in which the ego or selfhood stands outside the subject, who remains in heaven lying on a couch, an empty form waiting to be reinvested with a new identity. The exegesis of the "real ... Self" (E $109 ; 15: 11$ ) is by no means simple, but involves reversal and overturning. The famous image of the vortex, to which we shall return, is one of Blake's most striking figures for the reversals necessary to reading correctly and for the way they first impinge on us as a proliferating psychic chaos. As Milton falls like a "wintry globe" into the "Sea of Time \& Space," he enters a vortex in which "what was underneath soon seemd above / A cloudy heaven mingled with stormy seas in loudest ruin" $\left(\mathrm{E}_{1} 10 ; 15: 39-46\right)$. This disorganized state of affairs in which the world is inverted parodies the way Milton has made the spectrous undergrowth of his warped system into a heaven of transcendent principles. At the same time, these lines have the effect of defamiliarizing Milton's perversity, of exposing his system as what Schelling calls an inverted world that demands a counterreading: a reading that takes the form of a dialectical rather than a simple reversal. Blake would not have known Schelling but certainly knew Boehme, who is the source for the latter's view that opposites are interimplicated so as to make the negative into the ground of the positive. In Blake's terms, Milton is not his negation but his contrary, and the latter's inverted world contains enabling traces of Blake's vision. Just as the fall into the vortex registers on the character Milton as an optical jolt that occurs only because he is falling and sees things upside down, so it engenders in us a desire to rectify an unnecessary distortion of vision and functions as a hermeneutic signal to make us correct what the inversion parodies. The passage is thus a mise-en-abime of the larger text, figuring as a problem in perception what is more extensively narrated as Milton's paradoxical reversal of himself: his return from the dead to a living world that turns out to be dead, his return to a past that turns out to be the future. The vertigo of these reversals, though potentially endless, is stabilized by their association with religious paradox and their anchorage in a hermeneutics of conversion.

In retrospect, we must take this scene of reading as narrating our own mental travel through the inscape of Blake's corpus. The weeds of death in which Milton becomes entangled as he falls into the sea recall the 
Urizenic chaos of Experience. In the early texts Blake had shaped that world into the "wintry globe" he describes here. This process of "conglobing' or 'englobing' in which Blake images a fallen creative activity that is both constructive and constrictive is also described at the beginning of Jerusalem: "There is a Void, outside of Existence, which if enterd into / Englobes itself \& becomes a Womb" (E144; 1:1-2). The globe, visually associated in Urizen with the globule of blood, is the aborted fetus created by the poet, who is a spectral and misguided version of Urthona. In a very different way Blake's early texts also conglobe a miscreated vision: a vision bitterly critical of Milton but, as we shall see, capable of negating only Milton's system of salvation and not his vision of the fall. That criticism, Blake now insists, can be seen not simply as harrowed by the anxiety of influence but as the self-disintegrative prelude to the major prophecies. That the early Blake could only reinscribe Milton, and that Blake's Milton revisits the site of his own early work, is marked by the fact that it begins with a reduced repetition of The (First) Book of Urizen, announcing itself as the second or perhaps third book of Urizen, now seen from a higher point on the spiral of understanding $(\mathrm{E} 96 ; 3: 1-43)$. We are also reminded that Milton is Blake's redeemed specter by the doubling of the two in a circular exchange in which Blake reading Milton sings the bard's song, which inspires Milton to reread himself so that he can enter Blake's left foot and enable him to write.

Milton is, in other words, Blake's poetic equivalent to Schleiermacher's Compendium. In it he not only stages the agon of reading as a process in which truth must be arrived at through negativity, he also begins to articulate rules of exegesis to limit the dissemination of meaning in his canon. These have to do with both detail and structure, and the rules that govern detail must be understood in the context of structure as a process rather than a static system. At the level of detail, one of the more prominent strategies of interpretive containment is the organization of the canon in terms of binary oppositions such as the distinction of contraries from negations, or the division of people into three classes: the 'redeemed' and the 'reprobate,' on the one hand, and the merely negative 'elect,' on the other. Although the notion of contraries is present as early as The Marriage, it is not opposed to the category 'negation,' which allows us to segregate as irrelevant whole areas of experience with which the early Blake engages in ways that threaten the closure, if not the intellectual vigor, of his dialectic.

The division into classes likewise limits ambiguity. Thus the uncomfortable proximity of the 'organized' innocence projected in the Lyca poems to the 'unorganized' version of the Songs of Innocence in which they were first included can be rationalized in terms of Bloom's characterization of the bard as merely 'redeemed,' unable to imagine an Eden 
that does not relapse into Beulah. ${ }^{18}$ As the redeemed speaker occupies the uncertain ground between reprobate and elect, so, too, his idea falters between the organized and the unorganized without really calling into question the possibility of organized innocence. Blake's binary oppositions, as this example suggests, are tenuously woven into a more complex field of three or sometimes four terms. Intertwined in the notion of classes is a third term that unsettles the opposition of the reprobate and the elect and a binary opposition that tries to restructure the triad by making the 'redeemed' a contrary aligned with the 'reprobate' and completely separate from the negation constituted by the 'elect.' As we try to read Blake's texts in terms of the grammar he provides for them, they keep slipping away from us. Satan in The Four Zoas "never can be redeemed in all Eternity" (E380; viii.381), and in Milton Satan or the Spectre is a negation $\left(\mathrm{E}_{142} ; 4^{0}: 34\right)$. Yet Milton, surely an imperfect (redeemed) version of Urthona, identifies himself with Satan or the specter $\left(E_{139} ; 38: 29\right)$. It is unclear whether the Spectre, whom Los tyrannically puts to work at his forge, is Los's contrary as Reason is the outward circumference of energy, or whether he actually negates the creative project. In all probability 'negations' and 'contraries' were themselves states that Blake passed through, feeling sometimes that his art was self-consuming, and at other times that he must enter the heart of his own darkness to make the void a womb.

The fact that Blake's classifications are states that he moves through rather than the 'langue' that governs particular narrative articulations suggests that they have only a heuristic status. Yet once again Milton tries to contain the disseminative implications of turning Blake into his own reader by making his rules provisional resting points in a hermeneutics of process. The text introduces a historical perspective committed not to relativism but to a progressive, universal poetry in which poet and reader are joint laborers in the teleological revisioning of earlier texts. Contradictions are an inevitable part of forging this coherence. Like Hegel, Blake sees the structure of his system as immanent and emergent rather than synchronic. Perhaps the best model for this notion of structure is the paradigm assumed by Goethe in his analysis of anatomical structure and developed by Dilthey into an analogy for the reading of literary structures and canons. When he made the discovery that people as well as animals had an intermaxillary bone, Goethe found that a component which served a particular purpose in one kind of structure could be adapted to a different structure as the species evolved. For Dilthey, Goethe's discovery was a crucial part of the intellectual climate that shaped hermeneutic assumptions about the relation between part and

${ }^{18}$ Blake's Apocalypse, pp. 130-32. 
whole. It "established a case in which a uniformity of structure given in the original design may exist in contradiction to the requirements of the completed structure; so the structural part in question had to be adapted to these requirements through a later coalescing of parts which originated separately." 19 The authorial canon may seem composed of parts that pull in different directions, and the individual text may similarly contain unassimilated surpluses. But Dilthey's paradigm gives us a way of reconceiving discrepant elements within the ongoing process of the text's structure. Blake's familiarity with the model would have come from its use in the increasingly vexed area of biblical hermeneutics, as an explanation of how a canon that lacked a single author(ity) could still be an authoritative whole. Milton is, in fact, an enactment of the paradigm. Beginning with a text that exceeded its own bounds in being of the devil's party, it adapts Milton to the needs of a later structure; gathering up parts of Blake's own corpus that originated separately, it struggles to idealize and unify them.

For strategic reasons the later prophecies will not be our concern. Although we have read Milton hermeneutically, it is clearly possible to uncover in it asymmetries between the mimetic, hermeneutic, and reflexive levels similar to those discussed in the Biographia. For instance, as Milton's prophetic reader, Blake reinvents him, but instead of transferring the power of re-vision from author to reader, he has Milton enter his body so that Blake can derive his authority from what he has created as reader. This displacement of power between Milton and Blake can be seen as the symptom of an uneasiness about the prophet's power, which has no origin and for which one must therefore create a genealogy that produces power as effect rather than source. The same structure of displacement unsettles the status of Blake and Milton as historical 'figures' outside the text and characters inside it. Thus, it is entirely possible to see the late prophecies as the work of a less than resolved soul. Nevertheless, thematic and unreflexive readings of these poems have given them a place in the critical canon which now needs to be questioned. Emphasis on Milton and Jerusalem, in other words, has naturalized a hermeneutic reading of the earlier texts because it seems to be what Blake 'finally' wanted. To see the corpus from the perspective of these earlier texts is to recover the heuristic potential of the texts as a whole. Such a shift of terrain will unsettle the paradigmatism of part and whole implicit in the hermeneutic circle of the canon. It will allow us to see the parts as having a certain autonomy from the later whole, and to see the whole as inscribed in the parts rather than as transcending them.

${ }^{19}$ Wilhelm Dilthey, "The Schleiermacher Biography," Dilthey: Selected Writings, ed. H. P. Rickman (Cambridge: Cambridge University Press, 1976), p. 62. 
The Cubist Whole: Blake's Perspectivism

The foregrounding of part over whole characteristic of Blake's early works is best summed up by the term 'perspectivism.' This description of Blake's technique is by no means new. It is of ten pointed out that in Milton we see the action from Milton's point of view as he descends into Generation. But his immortal self simultaneously sleeps on a couch in heaven, so that we also see things from the perspective of eternity. Not surprisingly, discussions of Blake's perspectivism generally assume a synchronicity of part and whole that is, at best, relevant only to Milton and Jerusalem. Perspectives are aligned in terms of the hermeneutic schema of single to fourfold vision that Blake later developed, and are seen as parts of a totality. Susan Fox thus associates Blake's layered organization of multiple perspectives in Europe and Milton with a simultaneity that substitutes visionary for linear time. Perspective, according to her, is an angle of deviation, to be measured in relation to "the comprehensive criterion of eternity." 20 But in the early texts perspectives are juxtaposed rather than cinematically superimposed, the bard's song being counterpointed against Earth's answer and not hegemonically placed above it. The fact that we pass through various perspectives serially, and that we cannot occupy them at the same time, suggests that we need a new perceptual vocabulary to describe the perspectivism of the early Blake.

It may be more accurate to see Blake's perspectivism as cubist than as visionary, and thus to recognize its nonhierarchical nature. Albert Gleizes and Jean Metzinger point out that their aim is not to make the spectator juxtapose the six faces of the cube so as to recompose them into an organic whole: "An object has not one absolute form, it has several. . . A As many images of the object ... as minds to understand it."21 Abandoning the concepts of an absolute space and time constructed from a fixed point of view, cubism sees things as existing in relation to each other and as appearing differently from different perspectives. Wylie Sypher describes the cubists as breaking open "the volumes of things by spreading objects upon shifting interrelated planes ... planes which give an illusion of closure and depth but which are always moving and readjusting themselves to one another." 22 The incomplete contours and the conspicuous use of surfaces so as to restate three dimensions in two remind us that 'reality' is known as a series of appearances, that volumes (as we perceive them) are surfaces that we

${ }^{20}$ Poetic Form in Blake's Milton (Princeton, N.J.: Princeton University Press, 1976), p. 9. 21 "Cubism," in Robert L. Herbert, ed., Modern Artists on Art: Ten Unabridged Essays (Englewood Cliffs, N.J.: Prentice-Hall, 1964), p. 13.

${ }^{22}$ Rococo to Cubism in Art and Literature (New York: Vintage, 196o), pp. 267, 270. 
endow with depth. It is to such a use of surface rather than to mythic stylization or to an allegorical deferral of meaning beyond the temporal world that we can attribute the lack of interiority of Blake's early characters and the flatness of his narrative world. His 'outlining' of characters like Oothoon and Thel does not give us, as in abstract art or for that matter archetypalism, the essential form of the character, but rather its appearance. On the other hand, it does not reduce character to surface, as if there were no inside to be constructed. For surfaces, as the outward bound of volumes, invite us to construct those volumes that the text does not wish to fix in writing. Such a use of surface is phenomenological, in that reality is not denied but does not exist as a transcendental signified.

The analogy is of course inexact, since cubist compositions are quietly removed from the social arena, concerned with perception and not with moral commitments. Blake, on the other hand, is also a poet of melodrama and climax, of spectacular cultural battles that promise decisions, as in nineteenth-century historical painting like that of Delacroix. The will to understanding and power inherent in Blake's metaphysical and historical subject matter is engaged in a passionate struggle with a method of construction that constantly situates it. Cubism does, however, provide a suggestive analogy for understanding, on a technical level, Blake's departure from realism. It stops short of the radical antirealism of abstract art, which is essentialist and structuralist in positing a world of pure mental forms outside phenomena. Cubism is also quite different from symbolism, which denies the empirical reality of the world and makes it into a forest of symbols that are yet to be decoded rather than allegorically transparent. It sees reality as present in appearances that are partly constructed by the eye, such that the ground of this 'reality' can never quite be located in fact or fiction.

It is this phenomenological construction of 'reality' as the shifting conjunction of outside and inside that seems most relevant to the early Blake. Allowing as it does for the role of perception in (re)covering reality, the cubist aesthetic lends itself to a writerly element in texts. Wylie Sypher argues that "the cubist object has ... a plural identity apparent only as a passage between thing and idea, fact and fiction." 23 To put it differently, cubism is perceptually self-critical: it denies us a point of view and juxtaposes different perspectives in a space where they must know their own margins. It neither takes 'reality' inside a single mind, nor does it see things from some omniscient perspective that naturalizes point of view as objective. Rather, the cubist camera is objective in taking in several perspectives, but it does not organize the field of 
vision in an optical hierarchy that lets the viewer come to rest in one of them, nor does it claim the omniscience of encompassing several perspectives.

Blake's own phrase from "The Mental Traveller" best describes the perceptual structure he creates. "The Eye altering alters all" $\left(\mathrm{E}_{4} 8_{5} ; \mathrm{l} .62\right)$ does not proclaim an idealist recomposition of reality by the inward eye, but suggests a complex phenomenological interchange between inside and outside in which the verb 'altering' describes both what the eye does to the object and what happens to the eye in the process. The eye is constantly moving, seeing things in new ways, but being altered by those perceptual shifts so that it must keep reenvisioning what it 'sees.' As the punning use of the word "eye" suggests, this process situates the subject as an effect of its perceptions, so that the 'I' is always already a reflexive instrument: an eye that looks at itself. The diacritical account of eye and object as mutually altering applies to the relationship between reader and text as well as to the author-text relationship, thus generating, as we suggested earlier, a writerly text. Just as the text is the site of intersections, mutually opening and disruptive, between the author and 'things,' so, too, it is also the shifting ground on which reader and author keep exchanging positions.

Perhaps closest to this view of the text as perspectival is Donald Ault's discussion of transformational structure. In Visionary Physics Ault had discussed Blake's use of an 'anti-Newtonian' narrative form in which causal and linear relationships between events were disrupted, as a way of replacing chronological with visionary time. By contrast, his recent discussion of The Four Zoas sees nonlinear narrative as antimetaphysical and thus incompatible with the grasping of a transcendental signified, however fluid. ${ }^{24}$ To say that "the Eye altering alters all" is not to claim that one must see 'through' and not 'with' the eye. Rather, it is to acknowledge that 'with' and 'through' are intertwined, because the eye is not just a window through which one sees into eternity but also a mirror that reflects itself. Thus for Ault, Newtonian or conventional narrative would assume that "behind the text lies a single unified field" that appears different at different times only because we have not fully grasped it. Correspondingly, it would assume a "rigid subject-object division" between reader and text, in which the narrative is in the text, and the reader's function is to understand it. For the notion of an underlying world "that supports the details of the surface narrative and is signified by them," Blake substitutes "a deep structure that is a transformational

24Visionary Physics: Blake's Response to Newton (Chicago: University of Chicago Press, 1974); "Re-Visioning The Four Zoas," in Hilton and Vogler, eds., Unnam'd Forms, pp. 1054o. Ault does not situate himself in relation to contemporary theory, but this is what I take him to be doing. 
process" generated "by the operations of the poem's narrative surface." The consequence is an intertextual process in which the narrative is a "transformative agent through which reader and text mutually alter and revise one another." 25 A related phenomenon has been noted by Thomas Frosch, who argues that although the components of Blake's imaginary landscapes "singly offer the eye no difficulty," their "interrelations and the transitions from one to another" are too rapid for us to visualize. ${ }^{26}$ Though Frosch sees this decomposition of the visual surface logocentrically, as recentering the text at the aural level of prophecy, it is equally possible to see it as deconstructing stable representation by making us aware of how the text shifts even as we try to visualize it.

The coupling of Blake with perspectivism is likely to be troubling to those who think of him as a strenuously affirmative writer. But as Alexander Nehamas has observed with reference to Nietzsche, perspectivism does not have to be relativism. It is simply an admission that one's own point of view is not uniquely privileged and that there is no synoptic point of view one can adopt to attain that privilege. This renunciation of authority comes from the recognition that different points of view cannot be "smoothly combined" because they do not necessarily bear on the same object. That we differ from each other because we are talking about different aspects of the object, and that there is no 'object' apart from its appearance in discourse, is the surest obstacle to the creation of a common language that needs no further rereading. Thus, as we shall see in Thel, the positions of the cloud and of Thel's final speech cannot be reconciled or hierarchized, because they are not really talking about the same thing except in a superficial sense. But this does not mean that perspectives are completely disjoined from one another, for that would lead to a hegemony of the subjective in which partial vision is reprivileged as the only alternative to an impossible total vision. Each approach, as Nehamas argues, "is capable of correcting itself, and many can incorporate new material. .. . What is not possible is that at some point we can incorporate 'all' the material there is into a single approach." 27

One consequence of a transformational view of the text is a decoupling of perspectivism from nihilism. Perspectivism need no longer paralyze (intellectual) action, as is assumed by so many who see political and deconstructive criticism as incompatible. The undecidability of the text is paralyzing only if we make difference a negative hypostasis of logocentr-

${ }^{25}$ Ault, "Re-Visioning The Four Zoas," pp. 106-8, 129.

26The Awakening of Albion: The Renovation of the Body in the Poetry of William Blake (Ithaca, N.Y.: Cornell University Press, 1974), pp. 111-12.

${ }^{27}$ Alexander Nehamas, Nietzsche: Life as Literature (Cambridge, Mass.: Harvard University Press, 1985 ), pp. 49-52, $5^{1}$. 
ism by assuming that there is some truth about which we can only write texts. But by making the text a transformational field, Blake gives up any notion of an absolute truth and creates a form sensitive to the historicity of the text as the site of individual and cultural exchange. This view of the early Blake is obviously very different from that of Jerome McGann, who sees Blake's decision to be his own author, editor, and publisher as an attempt to privatize production and reception. ${ }^{28}$ But resistance to corporate technology, though obviously a 'romantic' position, is not necessarily a retreat from political engagement. Blake's method avoids a mass consumerism that would absolve his readers from the need to put things together for themselves. This resistance recognizes that the lion and the ox do not "see alike" and is thus potentially an openness to other points of view. For Blake, too, must keep putting things together differently, avoiding the homogenized vision of a text finalized for commercial publication. Blake's method of production is in fact an attempt to avoid the alienation of labor: both ours and his. In creating a text that is open to revision from its readers, he also tries to avoid the alienation of the author from the dissemination of his text: the death of the author whose resistance to reappropriation makes him irrelevant and thus creates a dualism of past and present in which reading becomes a reification of the text as cultural error.

It is useful to return to the concept of writing as 'work,' both to specify the nature of Blake's perspectivism and to qualify charges of privacy. The extraordinary coherence of the early texts at the level of the issues they address allows us to speak of Blake's "work" in the sense of labor. But their stylistic diversity complicates any attempt to naturalize perspective by abstracting what is said from how it is said, and thus to make labor yield a "work" in the classic sense of a finished product. The figure of labor can be set against the image of mental fight, dramatized in battles between zoas and their specters that promise some kind of epic resolution. Depictions of characters as laboring at a forge, weaving, or tilling suggest a more complex participation in an economy, a semiotics of exchange. The metaphor of labor helps to distinguish Blake's poems from Yeats's "vacillations," from a dramaturgy of stylized masks that the subject inhabits rhetorically rather than existentially, and that may indeed be a form of relativism. Labor suggests an attempt to produce something, a belief in the value of what one is doing as an activity if not as something that continuously corresponds to truth. But labor does not necessarily result in progress, except in very local ways: hence the early

${ }^{28}$ Jerome McGann, A Critique of Modern Textual Criticism (Chicago: University of Chicago Press, 1983), pp. 44-47. 
Blake's arrangement of his text in a nonlinear array ${ }^{29}$ that prevents the reading process from becoming complacently teleological. The construction of the individual text in movable parts is repeated on a larger scale by the construction of Blake's work as an intertextual field: a field in which our tendency to use chronology as a way of arranging poems in an evolutionary narrative is blocked by the way Blake keeps reproducing earlier texts along with later ones, uncertainly refiguring and reinhabiting what he has 'left.'

\section{Counterhermeneutic: The Marriage of Heaven and Hell}

As Milton is the later Blake's statement of a traditional hermeneutic, so it is in The Marriage of Heaven and Hell that the earlier Blake's view of the text as heuristic emerges. A rereading of the Western tradition, The Marriage introduces what Nietzsche and Foucault were later to call a genealogical approach that entails both a view of language itself as the site of ideological (de)construction and a view of reading as the (re)generation of ideas. Genealogy locates the text as a perspective. For although The Marriage is the early Blake's most credal text, its mythmaking occurs at a threshold between the visionary sense of myth attributed to the romantics by Bloom and Frye, and Barthes's revisionary sense of mythologies as attempts to naturalize the cultural origins of sign systems. One can trace this second notion of mythology back to the rise of anthropology in the romantic period, and to Schelling's awareness in The Philosophy of Mythology that myths are historical expressions of the cultures that produce them. But where Schelling naturalizes myths within a teleological movement that sees them as progressively truer, Blake is strikingly aware of myths as linguistic constructs. Thus, his ideological criticism is conducted through a semiological deconstruction that implicates Blake himself in his own practice, in a way that the simple intellectual dismissal of his precursors would not. In a curious anticipation of Nietzsche's Genealogy of Morals, Blake begins The Marriage by focusing on the signifiers 'good' and 'evil' and their purely customary relationship to the qualities they represent in a culture that uses binary rhetoric to naturalize its morality. Such reflections on the sign clearly apply to 'Blake' himself: if energy is merely 'called' evil by Miltonic Puritanism, then who is to say that what Blake calls energy is not itself a name for something else? Genealogy studies belief as the representation of a cul-

\footnotetext{
29I borrow this term from McGann, "Some Forms of Critical Discourse," Critical Inquiry
} $11(1985): 402-6$. 
turally interested will-to-power. Intermittently, Blake will open himself to genealogical reading, as when he leads the angel through hell in an attempt to convince him that it is really heaven, and then concedes that "we impose on one another" $\left(\mathrm{E}_{42} 2 ; 20\right)$. As significant is the memorable fancy in which he traces a belief in the poetic genius back to the Hebrews, only to assign this belief persuasive rather than constative status, warning us against a visionary discourse that may be the imperialism of a small sect denied the status of capital letters: "This, [said Ezekiel], like all firm perswasions, is come to pass, for all nations believe the jews code and worship the the jews god, and what greater subjection can be" (E39; 13-italics mine).

Crucial to the text's strategy of defamiliarization is its construction of a 'genealogical' as opposed to a 'genetic' narrative: one that exposes the basis of language in power. Genetic narratives legitimate themselves through causal structures that make their vision seem natural. They move from beginning to end so that what they narrate seems to happen, either factually or psychologically. Thus, the creed of The Prelude 'grows' out of childhood experiences and that of Jerusalem arises from psychological need. The Marriage, by contrast, does not begin: it erupts, in an attempt at beginning whose obscurity makes us aware of beginning as a structural function. Thereafter it proceeds discontinuously, through a series of abstract propositions alternating with visionary anecdotes. The anecdotes take the place of narrative and try to show the antinomian discourse of energy as happening in the world. But because of their brevity, it is as if that attempt must happen over and over again. The abrupt shifts in The Marriage convey the structure of discourse as interruption or imposition rather than origination, and they expose a certain arbitrariness in these interruptions. Blake does in fact provide 'origins' for his myth in locating it as a transvaluation of Milton or an overgoing of Swedenborg, and in giving it an ancestry in the Hebrew prophets. But these tracings are genealogical rather than genetic, because they reveal the self-interest that produces an act of linguistic usurpation, or that legitimizes a discourse by giving it an ancestry that exposes its tribalism. As if to protect the reader from this usurpation, Blake deconstructs his precursors through word games that give his own counteridentity an unstably linguistic existence. An example is the criticism of Paradise Lost:

Those who restrain desire, do so because theirs is weak enough to be restrained; and the restrainer or reason usurps its place \& governs the unwilling....

The history of this is written in Paradise Lost. \& the Governor or Reason is call'd Messiah. 
And the original Archangel or possessor of the command of the heavenly host, is calld the Devil or Satan and his children are call'd Sin \& Death

But in the Book of Job Miltons Messiah is call'd Satan.

For this history has been adopted by both parties $\left(\mathrm{E}_{34} ; 5\right)$

By playing Job against Milton, Blake reveals the arbitrariness of the names that Milton uses to label moral positions as real. What is Messiah to Milton is Satan from another perspective whose character as mere inversion marks it as no truer than what it replaces. But the arbitrariness of moral signifiers becomes truly vertiginous as we approach what seems to be Blake's 'solution':

It indeed appear'd to Reason as if Desire was cast out. but the Devils account is, that the Messiah fell. \& formed a heaven of what he stole from the Abyss

This is shewn in the Gospel, where he prays to the Father to send the comforter or Desire that Reason may have Ideas to build on, the Jehovah of the Bible being no other than he, who dwells in flaming fire. $\left(\mathrm{E}_{34}-35^{;} 5^{-6}\right)$

Given the confusion about who Messiah is, is Blake in the spirit of the fourth memorable fancy saying that Satan or energy formed the true heaven in the abyss conventionally perceived as hell? Or is he saying, as the next proposition suggests, that Christ borrowed from Satan the passion necessary for Reason to "have Ideas to build on"? The first possibility dismisses 'reason' where the second redefines it. Generating one possibility from the other, Blake makes his ideology a transformational discourse that exceeds his various attempts at propositional paraphrase. $\mathrm{He}$ also defamiliarizes the names by which religious systems identify themselves. 'Messiah' and 'Satan' are simply functions in a narratology: they have been and will be differently occupied by various systems according to the self-interest of each.

Blake's willingness to grant his system an existential but not an epistemological truth is related to his unusual theory of language as difference. In his celebration of the ancient poets, he places myth at the intersection between theology and semiology, and he insists that language must remain vitally metaphorical in Shelley's double sense of the term: ${ }^{30}$

The ancient Poets animated all sensible objects with Gods or Geniuses. ... .

And particularly they studied the genius of each city \& country, placing it under its mental deity.

${ }^{30}$ See my discussion in Chapter 10. 
Till a system was formed, which some took advantage of \& enslav'd the vulgar by attempting to realize or abstract the mental dieties from their objects: thus began Priesthood.

Choosing forms of worship from poetic tales. $\left(\mathrm{E}_{3} 8 ; 11\right)$

Although the opposition between concrete and abstract thinking is typically 'romantic,' mythic language, unexpectedly, is visionary but not logocentric. Blake opposes the Cartesian separation of inside and outside, and endows material objects with mental deities so as to affirm the presence of imagination in the world. But his monism does not result in an identity of mind and nature that hypostatizes mental categories. Anticipating Nietzsche, he insists that myth remains imaginatively vital only as long as it is recognized to be a moving army of metaphors. To turn it into dogma amounts to an alienation of imaginative labor in which the dualism of mind and its objects resurfaces inside an 'identity' of the two that masks a lack of engagement between the mind and its atrophied products.

Blake's theory of language as a transformational practice leads to a sense of reading as dissemination, such as we shall trace in Shelley's Defence. Many of the vignettes that make up The Marriage present scenes of rereading and play with the memorable fancies of a traditional hermeneutic. The section in which 'Blake' takes the angel through the void in order to show that the abyss is a product of distorted perception presents an early version of the vortex in which reading generates perceptual reversals so as to produce a corrected vision. The vortex is Blake's image for a hermeneutics of reversal that employs what Schelling calls irony and involution. Plate 14 likewise represents Blake's rereading of the tradition in terms of a hermeneutics of negativity in which he must unsay what has been said in order to liberate things as they should be from things as they are. It describes how he prints in the "infernal method, by corrosives, which in Hell are salutary and medicinal, melting apparent surfaces away, and displaying the infinite which was hid" (E39; 14). Although Blake in this text plays the role of reader and negates the surface of Paradise Lost so as to discover the infinite within it, what he also does is to give his own readers a way of interpreting texts like Urizen and Europe. But in this text at least the strategies of romantic hermeneutics are put forward with exuberant irony. Against the episodes in which he plays the revolutionary reader, revising Milton and Swedenborg from a more enlightened point on the spiral of history, we must set the anecdote in which Blake looks amusedly at the arrogance of his authorized version. In the final memorable fancy Blake describes the conversion of a resisting reader to his own perspective in a comic-strip narrative that 
has the angel turning blue, yellow, white, and then pink. The section is followed by the line "One Law for the Lion \& Ox is Oppression," as if to remind us that oppositional reading, not angelic submission, is true friendship.

That we must guard against a hermeneutics that turns prophecy into priesthood is something Blake emphasizes in the section on the printing house in hell, sometimes placed at the end (copy E). This section is of ten read straightforwardly as a description of how the visionary text is produced and then received by "Men" who take the forms of books and thus embody it. But the last phase in this process is highly problematic. In the fifth chamber the propagation of knowledge is still associated with a generative chaos: "In the fif th chamber were Unnam'd forms, which cast the metals into the expanse" $\left(\mathrm{E}_{40} ;{ }_{15}\right)$. For much of The Marriage Blake represents himself in intimate conversation with prophets and devils, and assumes that his readers will form a visionary company that hears his voice. Here he represents himself as a radical pamphleteer, cast out of an oral into a print culture and exposed to an economy of dissemination rather than circulation. Transmitted by unnamed forms instead of by an author who controls the circulation of meaning, the text enters a space where its identity seems at risk. But this space, described as an 'expanse,' stands in contrast to the imaginative contraction that begins with the reassertion of literary protectionism in the sixth chamber. For the bizarre image of people taking the "forms of books" and being "arranged in libraries" describes a process of reification in which passive readers become deadeningly identified with the commodities they consume.

By encouraging the independence of his readers, Blake allows us to see his myth as a perspective. But The Marriage is uniquely affirmative in allowing other points of view a theoretical existence without admitting them into the text. Blake marks the limits of his myth not by actually calling it into question but through a disjunctive interplay of styles that includes parody and high seriousness, dogmatic abstraction and fantasy. As Alexander Nehamas has said of Nietzsche, his stylistic pluralism

is his solution to the problem involved in presenting positive views that do not . . f fall back into dogmatism. . . His many styles make it impossible to get used to his presence and ... to forget it. They therefore show that his positions are expressions of one particular point of view besides which there may be many others. They show his perspectivism without saying anything about it, and to that extent they prevent his view that there are only interpretations from undermining itself. ${ }^{31}$

${ }^{31}$ Nietzsche, p. 40. 
Perspective is marked only through form. The individual sections of The Marriage do not challenge each other; rather, their brevity curtails any tendency to monumentalize their ideological constructions. At the same time, the text's proliferation of forms prevents its irony from becoming self-devouring, and results in a stylistic exuberance that makes scepticism only the outward circumference of imaginative energy. In The Marriage the reader plays with the possibility of other viewpoints. In Blake's other writings we begin a different kind of labor: the labor of distinguishing and combining perspectives, and of determining whether they can be combined at all. 